\title{
Effects of low-level stimulation of the septal area on two types of discrimination reversal in the rat'
}

\author{
P. J. DONOVICK AND J. S. SCHWARTZBAUM \\ UNIVERSITY OF WISCONSIN
}

The effects of continuous low-level electrostimulation of the septal area and other structures were examined with respect to reversal behavior in spatial(position) and brightness discriminations. Septal stimulation selectively impaired spatial but not brightness reversals, suggesting a closer relationship between the dysfunction and response perseveration as opposed to stimulus perseveration.

Several recent studies have shown that dysfunction in the septal area of the forebrain produced by lesions or low-level electrostimulation leads to impairment in reversal of spatial (position) discriminations (Kasper, 1965; Thompson \& Langer, 1963; Zucker \& McCleary, 1964). Zucker (1965) in work with cats has also reported deficits in reversal of a successive go-no-go discrimination and simultaneous object discrimination but the latter findings are not entirely consistent.

These results on spatial and go-no-go reversal can be interpreted in terms of a general response-inhibition hypothesis (McCleary, 1961) which relates the impairment in reversal behavior to a difficulty in suppressing previously reinforced responses. But in a strict sense, the hypothesis assumes a more direct inhibitory role by septal components in the expression of somatomotor response (at some integrative level) relative to other associative and motivational processes mediating the response. The present study explores this question by comparing the effects of low-level stimulation of the septal area, and other structures, on reversals of a spatial (position) and brightness discrimination. These conditions permit an assessment of deficits that are expressed in response perseveration and stimulus perseveration based on prior training, and may therefore allow a more precise specification on the dysfunction.

Method

The Ss were 61 male Sprague-Dawley rats, weighing approximately $300 \mathrm{gm}$. All but six Ss in the control group were implanted stereotaxically with bipolar stainless-steel electrodes (.010 in.) in either the septal area, caudate, or overlying neocortex. The experimental groups received continuous low-level stimulation of the brain (100/sec., $0.5 \mathrm{msec}$. duration, "biphasic") at 25 to $35 \mathrm{uA}$. from Grass SD-5 stimulators as monitored by a Tektronix 502A oscilloscope.

Discrimination tests were conducted in an automated shuttlebox type of device (24 in. long, $10 \mathrm{in}$. wide and 12 in. high) divided into two equivalent compartments.
Each end panel contained a pair of levers, In-line digital display units to project stimuli, and a Davis feeder ( $45 \mathrm{mg}$ pellet) linked to a center foodwell.2 These components were programmed so that $S$ had to shuttle between compartments on successive trials, and, therefore, always to approach the discriminanda from the opposite side of the box. A partition provided a 4 in. opening between compartments and contained a motordriven gate that could be used to define intertrial time, although present test conditions allowed self-paced behavior.

Following surgery, Ss were placed on a food-deprivation schedule designed to maintain body weight at 300$320 \mathrm{gm}$, and were given a limited amount of training to respond to each of the levers and to shuttle between compartments. No discriminative stimuli were presented during this phase of the experiment. Tests were also run on self-stimulation in another lever box to approximate the threshold for any positive reinforcing properties of the stimulation $(0.5$ and $2.0 \mathrm{sec}$. trains of pulses).

For the simultaneous brightness discrimination, the bright stimulus had an intensity of $16 \mathrm{~mL}$ as measured by a MacBeth Illuminometer, and the dim stimulus, $.27 \mathrm{~mL}$. Each group was subdivided with respect to the reinforced stimulus during original learning (OL). The stimulus presentations, which alternated between compartments, followed a Gellerman order with noncorrection technique. Each daily session consisted of five warm-up trials, during which stimulation was introduced in experimental Ss, followed by 60 test trials. The Ss were run to a criterion of an average of $85 \%$ correct for two consecutive sessions. In the succeeding sessions, reward conditions were reversed for a total of three reversals.

Test conditions for the spatial discrimination were identical to the above except that no stimuli were projected in the display units, and either right or left response was reinforced consistently within a problem; Ss still rapidly learned to shuttle despite the absence of feedback from offset of projected stimuli. Each group was subdivided randomly with respect to the response reinforced during OL.

\section{Results}

Figure 1 presents the results of performance in session-1 of each reversal as an indication of perseverative tendencies. Analyses of variance of the brightness-discrimination revealed no group differences in stimulus perseveration. Although all groups 


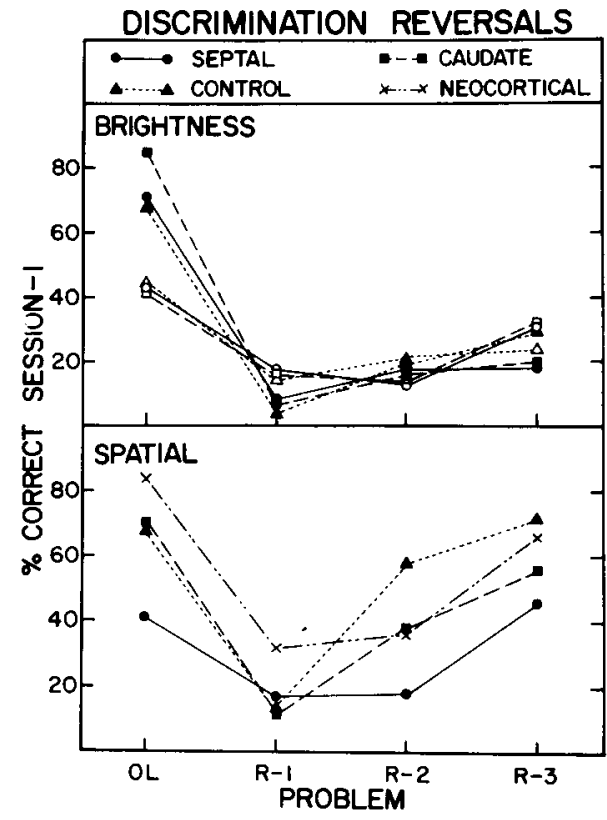

Fig. 1. Mean percentage correct in session-1 of original learning (OL) and of each of the reversals of a arightness and spatial (position) discrimination. Unfilled symbols in upper graph refer to groups for which dim stimulus was $(t)$ during $O L . N=6$ or 7 per group except Neocortical where $\mathbf{N}=5$.

showed pronounced perseveration, the same pattern of results was also obtained in session-2 of each reversal. Here, performance of the control group climbed from an average of $26.6 \%$ on $\mathrm{R}-1$ to $48.8 \%$ on $\mathrm{R}-3$, while the corresponding values for the septal group were 25.9 and $48.0 \%$. Analysis of the total errors madeduring OL and reversals disclosed highly significant effects relating to brightness (reflecting the greater effectiveness of the bright stimulus as a cue) and repeated reversals but no group differences.

By contrast, analysis of the error data on OL and reversals of the spatial problem revealed significant over-all group differences $(\mathrm{F}=4.06, \mathrm{df}=3 / 19, \mathrm{p}<.05)$ as well as reversal effects ( $F=24.86, \mathrm{df}=3 / 57, \mathrm{p}<.001)$. The septal group showed more variability during OL but was not generally deficient (septal vs. control: $\mathrm{U}=8, \mathrm{p}>.10$ ); subsequent lesion work also fails to indicate any deficiencies in learning of the spatial problem. Major group differences related to reversals (Group: $\mathrm{F}=3.25, \mathrm{df}=3 / 19, \mathrm{p}<.05$ ) where both septal and caudate groups, unlike the neocortical group, could be differentiated from the control group $(F=8.36$ and 7.57 respectively, $d f=1 / 10, p<.05)$. Septal stimulation in particular enhanced response perseveration in session1 of these reversals, with differences between septal and control groups exceeding the .05 level $(F=4.97$, $\mathrm{df}=1 / 10$ ). These findings have been confirmed in rats with septal lesions, although the effects were most pronounced in R-1 and R-2.

Finally, it may be noted that time measures of performance (total time/session) did not differentiate groups on either problem. But overall, the brightness problem proved substantially more difficult than the spatial problem, requiring a mean total of 28 sessions for completion of $\mathrm{OL}$ and reversals compared to 11 sessions for the spatial problem.

Histological data showed that septal placements fell almost exclusively in the region of the medial septal nucleus and diagonal band at an AP plane of $8920 \mathrm{u}$ (Konig \& Klippel, 1963), presumably anterior to the precommissural distribution of the fornix. Caudate placements tended to be scattered in the head of the caudate at approximately the same AP plane, while neocortical placements varied from 9650 to $7470 \mathrm{u}$ about $1 \mathrm{~mm}$ off the midline and $1 \mathrm{~mm}$ deep. All septal Ss and 12 of 18 caudate Ss showed some evidence of selfstimulation, but never within the range of values employed during discrimination. Neocortical stimulation had no obvious positive reinforcing effect.

\section{Discussion}

These results, which confirm and extend the earlier findings, suggest a closer link between stimulationinduced septal dysfunction and response perseveration as opposed to stimulus perseveration. Insofar as the deficit related more closely to the stereotyped characteristics of the response, the results can be taken to support the view of a septal role in the inhibitory regulation of somatomotor activity, but not at a level of operation that can be specified in terms of approachavoidance or stop-go tendencies with respect to external stimuli controlling the behavior. If the latter were true, a more generalized impairment in reversal behavior would be expected. However, these conclusions must be tempered by the fact that brightness and spatial reversals undoubtedly differed along other critical dimensions besides response stereotype-indeed, the two problems varied in difficulty. In any event, it is of interest that the differential effects seen with low-level stimulation of the septal area are also found with septal lesions, although not with caudate lesions (Schwartzbaum \& Donovick, unpublished).

\section{References}

Kasper, P. Disruption of position habit reversal by septal stimulation. Psychon. Sci., 1965, 3, 111-112.

Konig, J. F. R., \& Klippel, R. A. The rat brain. Baltimore: Williams and Wilkins, 1963.

McCleary, R. A. Response specificity in the behavioral effects of limbic system lesions in the cat. J. comp. physiol. Psychol., $1961,54,605-613$.

Thompson, R., \& Langer, S. K. Deficits in position reversal learning following lesions of the limbic system. J. comp. physiol. Psychol., 1963, 56, 987-995.

Zucker, I. Effect of lesions of the septal-limbic area on the behavior of cats. J. comp. physiol. Psychol., 1965, 60, 344-352.

Zucker, I., \& McCleary, R. A. Perseveration in septal cats. Psychon. Sci., 1964, 1, 387-388.

\section{Notes}

1. This study was supported by Grants MH-10801 from NIMH, FR-0167 to the Wisconsin Regional Primate Center from NIH, and by the Research Committee of the Graduate School from funds supplied by the Wisconsin Alumni Research Foundation.

2. More detailed specifications of apparatus are available upon request. 